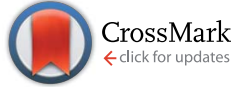

Cite this: Chem. Sci., 2015, 6, 1265

Received 26th August 2014

Accepted 12th November 2014

DOI: $10.1039 / c 4 s c 02596 b$

www.rsc.org/chemicalscience

\section{Atom-economic generation of gold carbenes: gold-catalyzed formal [3+2] cycloaddition between ynamides and isoxazoles $\uparrow$}

\author{
Ai-Hua Zhou, ${ }^{a}$ Qiao He, ${ }^{\text {b }}$ Chao Shu, ${ }^{a}$ Yong-Fei Yu, ${ }^{a}$ Shuang Liu, ${ }^{a}$ Tian Zhao, ${ }^{a}$ \\ Wei Zhang, ${ }^{a}$ Xin Lu*b and Long-Wu Ye ${ }^{\star a}$
}

\begin{abstract}
The generation of gold carbenes via the gold-catalyzed intermolecular reaction of nucleophiles containing relatively labile $\mathrm{N}-\mathrm{O}$ or $\mathrm{N}-\mathrm{N}$ bonds with alkynes has received considerable attention during recent years. However, this protocol is not atom-economic as the reaction produces a stoichiometric amount of pyridine or quinoline waste, the cleaved part of the $\mathrm{N}-\mathrm{O}$ or $\mathrm{N}-\mathrm{N}$ bonds. In this article, we disclose an unprecedented gold-catalyzed formal [3+2] cycloaddition between ynamides and isoxazoles, allowing rapid and practical access to a wide range of synthetically-useful 2-aminopyrroles. Most importantly, mechanistic studies and theoretical calculations revealed that this reaction presumably proceeds via an $\alpha$-imino gold carbene pathway, thus providing a strategically novel, atom-economic route to the generation of gold carbenes. Other significant features of this approach include the use of readilyavailable starting materials, high flexibility, simple procedure, mild reaction conditions, and in particular, no need to exclude moisture or air ("open flask").
\end{abstract}

\section{Introduction}

Catalytic transformations involving gold carbenes are arguably the most important aspect of homogeneous gold catalysis. ${ }^{1}$ Recently, the possibility of forming an $\alpha$-oxo gold carbenoid species via gold-catalyzed intramolecular or intermolecular alkyne oxidation by a $\mathrm{N}-\mathrm{O}$ bond oxidant (initially a sulfoxide), pioneered by Toste and Zhang, ${ }^{2 a, b}$ represents a significant advance in gold carbene chemistry, and various efficient synthetic methods have been developed based on this strategy. ${ }^{2}$ Compared with intramolecular alkyne oxidation, the intermolecular approach offers much greater flexibility as no tethering of the oxidant is required, and therefore it is more synthetically useful. ${ }^{3}$ However, this intermolecular approach is obviously not atom-economic as the reaction produces a stoichiometric amount of pyridines or quinolines, the reduced form of the

${ }^{a}$ State Key Laboratory for Physical Chemistry of Solid Surfaces, The Key Laboratory for Chemical Biology of Fujian Province and Department of Chemistry, College of Chemistry and Chemical Engineering, Xiamen University, Xiamen 361005, Fujian, P. R. China. E-mail: longwuye@xmu.edu.cn; Fax: +86-592-218-5833; Tel: +86-592-2185833

${ }^{b}$ State Key Laboratory of Physical Chemistry of Solid Surfaces, Key Laboratory for Theoretical and Computational Chemistry of Fujian Province and Department of Chemistry, College of Chemistry and Chemical Engineering, Xiamen University, Xiamen, 361005, Fujian, P. R. China. E-mail: xinlu@xmu.edu.cn; Fax: +86-592-2181600

$\dagger$ Electronic supplementary information (ESI) available. CCDC 1009902. For ESI and crystallographic data in CIF or other electronic format see DOI: $10.1039 / \mathrm{c} 4 \mathrm{sc} 02596 \mathrm{~b}$ corresponding pyridine $\mathrm{N}$-oxides or quinoline $\mathrm{N}$-oxides, as waste (eqn (1)), ${ }^{4}$ which may even deactivate the gold catalyst via coordination. ${ }^{5}$

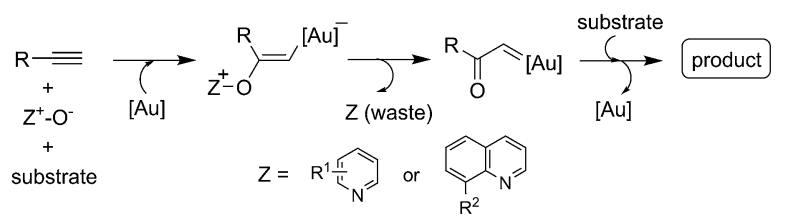

Access to the related $\alpha$-imino gold carbenes via gold-catalyzed nitrene transfer to alkynes, however, remains a highly challenging task. Here, it should be noted that: (1) the nitrene moiety is delivered via an outer sphere attack and no gold nitrene complex ${ }^{6}$ is involved in this case; this mode of nitrene transfer is distinctively different from many well-established nitrene transfer reactions; ${ }^{7}$ (2) this protocol would present alkynes as equivalents of $\alpha$-diazo imines, which are difficult to access as $\alpha$-diazo imines can readily cyclize into the corresponding 1,2,3-triazoles. To date, only limited success has been achieved in this type of gold-catalyzed nitrene transfer, mainly by the intramolecular reaction of alkyne and azide. ${ }^{8}$ For example, Toste and co-workers used azide as an effective nitrene equivalent and realized the first protocol for the generation of $\alpha$-imino gold carbenes in $2005 .^{8 a}$ Later, elegant studies on the synthesis of indoles from alkynyl azides were demonstrated by Gagosz $^{8 c}$ and Zhang, ${ }^{8 d}$ independently. Recently, several studies have invoked the intermolecular transfer of nitrene to alkynes 
by the use of iminopyridinium ylides as nitrene-transfer reagents, as disclosed by the groups of Zhang, ${ }^{9 a}$ Davies, ${ }^{9 b, c}$ and Liu. ${ }^{9 \boldsymbol{d}}$ However, similar to those of the above-mentioned goldcatalyzed intermolecular alkyne oxidations, a stoichiometric amount of pyridine was produced as the waste in these cases. Therefore, the exploration of intermolecular approaches to the generation of $\alpha$-imino gold carbenes, especially in an atomeconomic way, is very attractive to researchers. We envisioned that the $\alpha$-imino gold carbene intermediate $\mathbf{B}$ might be generated through the gold-catalyzed intermolecular reaction of ynamides $\mathbf{1}^{\mathbf{1 0}}$ with isoxazoles $\mathbf{2}$, which could be obtained in an efficient and modular manner following the synthetic routes shown in eqn (3) and (4) in Scheme $1 .^{\mathbf{1 1}}$ The carbene B, likely highly electrophilic, could then undergo an electrophilic cyclization to yield the final 2-aminopyrroles 3 , thus constituting a gold-catalyzed formal [3+2] cycloaddition (Scheme 1, eqn (2)). Herein, we report the successful implementation of this mechanistic design to a facile and practical synthesis of a wide range of polysubstituted 2-aminopyrroles, which are common structural motifs found in natural products and pharmacologically active molecules (Fig. 1) ${ }^{\mathbf{1 2}}$ and are difficult to access via traditional methods for pyrrole synthesis..$^{13}$ Most importantly, an $\alpha$-imino gold carbene is most likely generated as the key intermediate on the basis of both mechanistic studies and theoretical calculations, thereby providing a strategically-novel, atom-economic route to the generation of gold carbenes.

\section{Results and discussion}

At the outset, ynamide 1a and 3,5-dimethylisoxazole 2a were used as the reacting species and a series of experiments were performed in order to validate our approach. To our delight, the expected product 3a was indeed formed in $70 \%{ }^{1} \mathrm{H}$ NMR yield in the presence of $5 \mathrm{~mol} \% \operatorname{IPrAuNTf}_{2}$ (Table 1, entry 1). Then, various typical gold catalysts with a range of electronic and steric characteristics were screened (Table 1, entries 2-7), and $(\text { ArO })_{3}$ PAuNTf $_{2}(\mathbf{A r}=2,4$-di-tert-butylphenyl $)$ gave the best yield of the desired product (Table 1, entry 7). Somewhat surprisingly, AgNTf 2 could also catalyze this reaction in $50 \%$ yield (Table 1 , entry 8). Notably, without a metal catalyst, the reaction failed to give even a trace of $3 \mathbf{a}$, and $\mathrm{PtCl}_{2}$ and $\mathrm{Zn}(\mathrm{OTf})_{2}$ were not effective in promoting this reaction (Table 1 , entries 9-10). ${ }^{14}$ The reaction

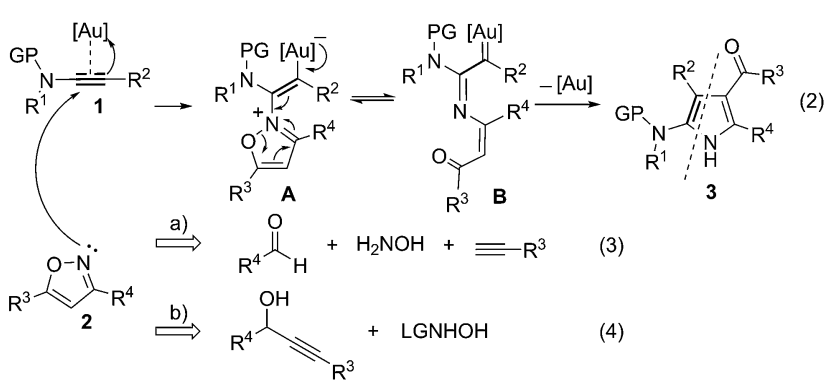

Scheme 1 Synthetic design for the atom-economic generation of $\alpha$ imino gold carbenes: formation of 2-aminopyrroles 3 through goldcatalyzed formal [3+2] cycloaddition between ynamides 1 and isoxazoles 2 .

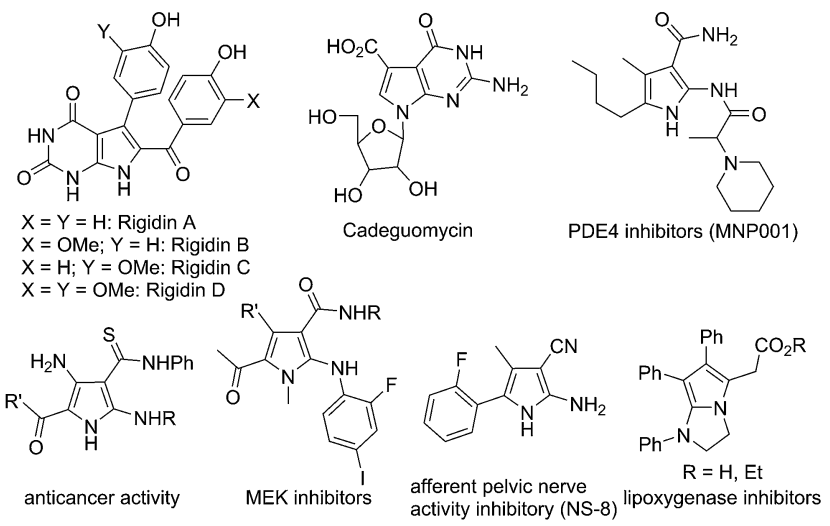

Fig. 1 2-Aminopyrrole subunit in natural products and bioactive molecules.

proved to be less efficient when it was performed at a reduced temperature (Table 1, entry 11). In addition, the use of 2 equiv. of $2 \mathrm{a}$ also gave the desired pyrrole $3 \mathrm{a}$ in $90 \%$ yield (Table 1 , entry 12).

With the optimized reaction conditions in hand, the scope of the transformation was explored. As seen from the results collected in Table 2 , the reaction proceeded smoothly with various ynamide substrates 1, and the yields ranged from 58\% to $96 \%$. For example, ynamides with different protecting groups, even the Ns group (Table 2, entries 4-5), readily gave the desired 2-aminopyrroles 3a-f (Table 2, entries 1-6). Of note, an excellent yield could be achieved in the case of an ynamide with an oxazolidinone moiety and no dimerization reaction was observed (Table 2, entry 6 ). ${ }^{15}$ When $\mathrm{R}^{1}$ is an allyl group, the

Table 1 Optimization of reaction conditions ${ }^{a}$

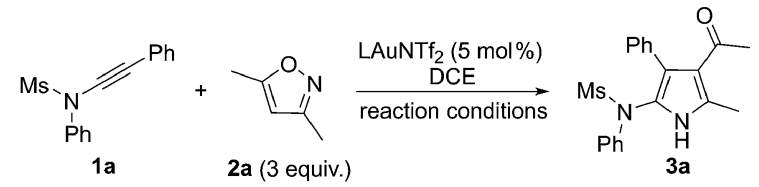

\begin{tabular}{|c|c|c|c|}
\hline Entry & Metal catalyst & Conditions & Yield $^{b}(\%)$ \\
\hline 1 & $\operatorname{IPrAuNTf}_{2}$ & DCE, $80^{\circ} \mathrm{C}, 3 \mathrm{~h}$ & 70 \\
\hline 2 & $\mathrm{Ph}_{3} \mathrm{PAuNTf}_{2}$ & DCE, $80^{\circ} \mathrm{C}, 3 \mathrm{~h}$ & 69 \\
\hline 3 & $\mathrm{Et}_{3} \mathrm{PAuNTf}_{2}$ & DCE, $80^{\circ} \mathrm{C}, 3 \mathrm{~h}$ & 54 \\
\hline 4 & Cy-JohnPhosAuNTf ${ }_{2}$ & DCE, $80^{\circ} \mathrm{C}, 3 \mathrm{~h}$ & 71 \\
\hline 5 & BrettPhosAuNTf $_{2}$ & $\mathrm{DCE}, 80^{\circ} \mathrm{C}, 12 \mathrm{~h}$ & 27 \\
\hline 6 & $\mathrm{Au}(\mathrm{III})^{c}$ & DCE, $80^{\circ} \mathrm{C}, 3 \mathrm{~h}$ & 34 \\
\hline 7 & $(\operatorname{ArO})_{3}$ PAuNTf $_{2}{ }^{d}$ & DCE, $80^{\circ} \mathrm{C}, 3 \mathrm{~h}$ & 95 \\
\hline 8 & $\mathrm{AgNTf}_{2}$ & DCE, $80^{\circ} \mathrm{C}, 3 \mathrm{~h}$ & 50 \\
\hline $9^{e}$ & $\mathrm{PtCl}_{2}$ & toluene, $80^{\circ} \mathrm{C}, 3 \mathrm{~h}$ & $<5$ \\
\hline $10^{e}$ & $\mathrm{Zn}(\mathrm{OTf})_{2}(10 \mathrm{~mol} \%)$ & DCE, $80^{\circ} \mathrm{C}, 3 \mathrm{~h}$ & $<5$ \\
\hline 11 & $(\mathrm{ArO})_{3} \mathrm{PAuNTf}_{2}{ }^{d}$ & $\mathrm{DCE}, 60^{\circ} \mathrm{C}, 5 \mathrm{~h}$ & 75 \\
\hline $12^{f}$ & $(\operatorname{ArO})_{3}$ PAuNTf $_{2}{ }^{d}$ & DCE, $80^{\circ} \mathrm{C}, 3 \mathrm{~h}$ & 90 \\
\hline
\end{tabular}

${ }^{a}$ Reaction conditions: $[\mathbf{1 a}]=0.05 \mathrm{M} ;$ DCE $=1,2$-dichloroethane. ${ }^{b}$ Measured by ${ }^{1} \mathrm{H}$ NMR using diethyl phthalate as the internal standard. ${ }^{c}$ Dichloro(2-picolinato)gold(III). ${ }^{d} \mathbf{A r}={ }^{2,4}$-di-tertbutylphenyl. ${ }^{e}$ 1a was decomposed. ${ }^{f} 2.0$ equiv. of 2 a was used. 
Table 2 Reaction scope for different ynamides $1^{a}$

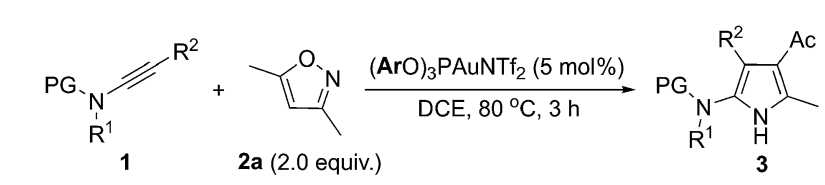

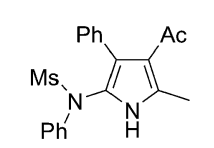

(1) $3 a, 89 \%$<smiles>[R5]N([Y5]#N)c1[nH]c(C)c(C(C)(C)C)c1-c1ccccc1</smiles>

(5) $3 e, 85 \%$<smiles>Cc1[nH]c(N(Cc2ccccc2)S(C)(=O)=O)c(-c2ccccc2)c1C(C)(C)C</smiles>

(9) $3 \mathbf{i}, 95 \%$

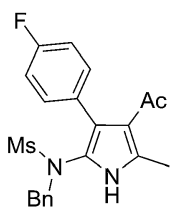

(12) $3 I, 95 \%$

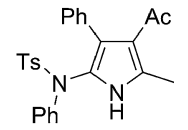

(2) $\mathbf{3 b}, 63 \%$

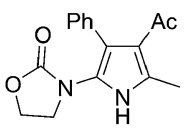

(6) $\mathbf{3 f}, 95 \%$

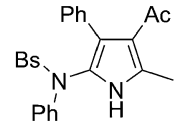

(3) $3 c, 80 \%$

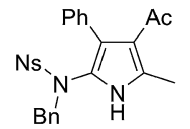

(4) $3 d, 75 \%$

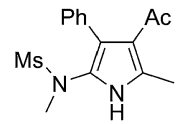

(7) $3 \mathrm{~g}, 68 \%$

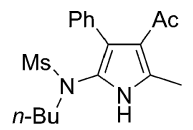

(8) $3 \mathrm{~h}, 85 \%$

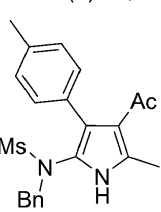

(11) $\mathbf{3 k}, 96 \%$

(10) $\mathbf{3 j}, 86 \%$<smiles>Cc1[nH]c(N(Cc2ccccc2)S(C)(=O)=O)c(/C=C/c2ccccc2)c1C(C)(Cl)Cl</smiles>

(13) $3 \mathrm{~m}, 75 \%$

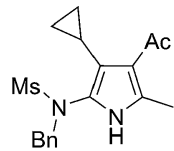

(14) $3 n, 58 \%$

${ }^{a}$ Reactions run in vials; $[\mathbf{1}]=0.05 \mathrm{M}$; isolated yields are reported.

desired $3 \mathbf{j}$ could also be formed in $86 \%$ yield, and no cyclopropanation product was formed (Table 2 , entry 10). ${ }^{16,5 g}$ Other aryl-substituted ynamides were also suitable substrates for this reaction, giving the corresponding functionalized pyrroles $\mathbf{3 k} \mathbf{k} \mathbf{l}$ in excellent yields (Table 2, entries 11-12). Interestingly, for styryl or cyclopropyl-substituted ynamides, this reaction still led to $75 \%$ yield and $58 \%$ yield, respectively (Table 2 , entries 13-14). The molecular structure of $\mathbf{3 a}$ was further confirmed by X-ray diffraction (Fig. 2). ${ }^{17}$

We next extended the reaction to different 3,5-disubstituted isoxazoles 2 . To our delight, the reaction of ynamide $\mathbf{1 i}$ with various isoxazole substrates 2 worked well under the above

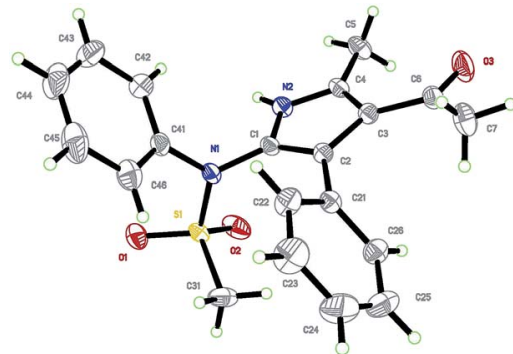

Fig. 2 Crystal structure of compound 3a.

optimized reaction conditions, giving versatile polysubstituted 2-aminopyrroles 3o-z in generally good to excellent yields. As summarized in Table 3, a range of aryl-substituted isoxazoles $\mathbf{2 c -} \mathbf{g}$ were successful $\left(\mathrm{R}^{2}=\right.$ aryl $)$, delivering the desired $\mathbf{3 p}-\mathbf{t}$ in $72-96 \%$ yield (Table 3 , entries $2-6$ ). In addition, when $\mathrm{R}^{1}$ is an aryl group, the reaction also worked well to afford the corresponding pyrroles 3v-w in excellent yields (Table 3, entries 8-9). Pleasingly, methyl 3-pyrrolecarboxylate 3x was formed in $90 \%$ yield from the corresponding isoxazole (Table 3 , entry 10). It should be mentioned that 3-formylpyrroles $\mathbf{3 y - z}$ could also be prepared in serviceable yields (Table 3, entries 11-12).

Interestingly, when the scope of the method was extended to fully-substituted isoxazoles $\mathbf{4}$, the reaction also proceeded well, allowing the convenient synthesis of deacylated polysubstituted 2-aminopyrroles 5. A series of readily-available substituted ynamides was first examined. The corresponding pyrroles 5a-d were obtained in $72-85 \%$ yield (Table 4 , entries $1-4$ ). Then, isoxazoles 4 with substituents at the 4-position were also investigated, giving the products $\mathbf{5 e - m}$ in mostly good to excellent yields (Table 4, entries 5-13). Notably, methyl 3-pyrrolecarboxylate $\mathbf{5 n}$ could also be obtained in $77 \%$ yield from the corresponding 4-substituted isoxazole, which is complementary to the above protocol based on the 3,5-disubstituted isoxazoles 2 (Table 4 , entry $14 v s$. Table 3 , entry 10 ). In particular, the 3,4diphenyl substituted isoxazole also reacted smoothly, delivering

Table 3 Reaction scope for different isoxazoles $2^{a}$

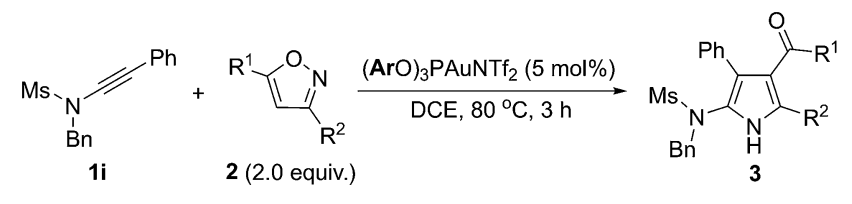

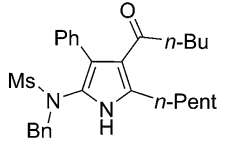

(1) $30,83 \%$<smiles>CCCC(=O)c1c(-c2ccc(Br)cc2)[nH]c(N(Cc2ccccc2)S(C)(=O)=O)c1-c1ccccc1</smiles>

(4) $3 \mathbf{r}, 76 \%$<smiles>CCCCC(=O)c1c(/C=C/c2ccccc2)[nH]c(N(Cc2ccccc2)S(C)(=O)=O)c1-c1ccccc1</smiles><smiles>COC(=O)c1c(-c2ccccc2)[nH]c(N(Cc2ccccc2)S(C)(=O)=O)c1-c1ccccc1</smiles>

(10) $3 \mathbf{x}, 90 \%$<smiles>CCCCC(=O)c1c(-c2ccccc2)[nH]c(N(Cc2ccccc2)S(C)(=O)=O)c1-c1ccccc1</smiles>

(2) $3 p, 86 \%$<smiles>CCCCC(=O)c1c(-c2ccc(C)cc2)[nH]c(N(Cc2ccccc2)S(C)(=O)=O)c1-c1ccccc1</smiles>

(5) $3 \mathbf{s}, 85 \%$<smiles></smiles><smiles>C[SH](=O)(c1ccccc1)c1[nH]c(-c2ccccc2)c(C=O)c1-c1ccccc1</smiles>

(11) 3y, $62 \%$<smiles>CCCCC(=O)c1c(-c2ccc(F)cc2)[nH]c(N(Cc2ccccc2)S(C)(=O)=O)c1-c1ccccc1</smiles>

(3) $3 q, 72 \%$<smiles>CCCCC(=O)c1c(-c2ccc(OC)cc2)[nH]c(N(Cc2ccccc2)S(C)(=O)=O)c1-c1ccccc1</smiles>

(6) $3 t, 96 \%$<smiles>Cc1[nH]c(N(Cc2ccccc2)C(=O)O[Na])c(-c2ccccc2)c1C(=O)c1ccccc1</smiles><smiles>C[SH](=O)(Cc1ccccc1)c1[nH]cc(C=O)c1-c1ccccc1</smiles>

(12) $3 z, 60 \%$

\footnotetext{
${ }^{a}$ Reactions run in vials; $[\mathbf{1 i}]=0.05 \mathrm{M}$; isolated yields are reported.
} 
Table 4 Reaction scope for different ynamides 1 and 4-substituted isoxazoles $4^{a}$

$$
\text { Ms } \underbrace{\mathrm{R}^{1}}_{1}
$$
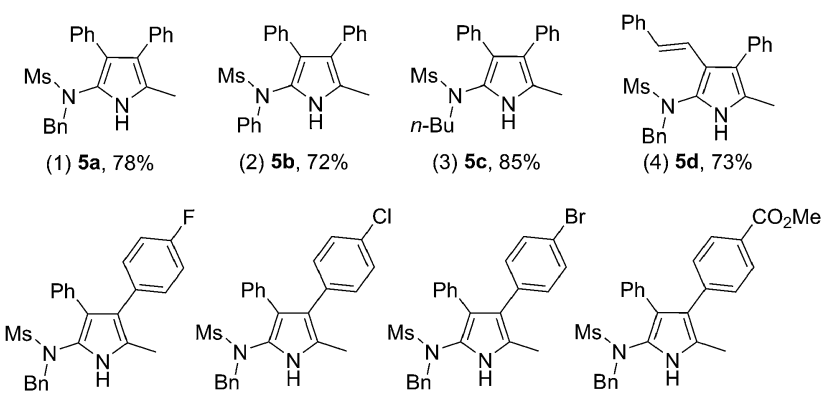

(5) $5 e, 78 \%$

(6) $\mathbf{5 f}, \mathbf{7 2} \%$

(7) $5 \mathrm{~g}, 81 \%$

(8) $5 \mathrm{~h}, 92 \%$

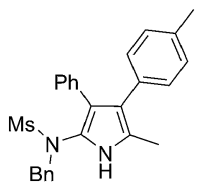

(9) $5 \mathbf{i}, 95 \%$

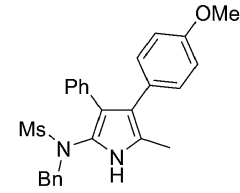

(10) $5 \mathrm{j}, 87 \%$

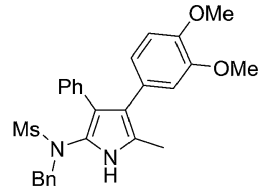

(11) $5 \mathrm{k}, 78 \%$

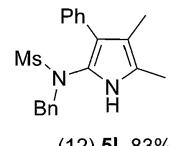

(12) $51,83 \%$
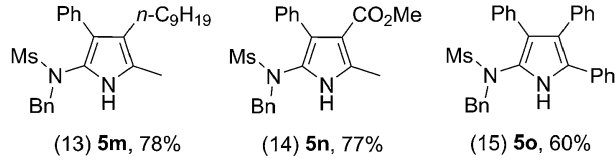

(15) $5 \circ, 60 \%$
${ }^{a}$ Reactions run in vials; $[\mathbf{1}]=0.05 \mathrm{M}$; isolated yields are reported.

the 3,4,5-triphenyl substituted pyrrole 5o in a respectable $60 \%$ yield (Table 4, entry 15).

To further test the practicality of the current catalytic system, a gram-scale reaction of $1.36 \mathrm{~g}$ of $1 \mathrm{a}$ and $1.07 \mathrm{~g}$ of $2 \mathrm{a}$ was carried out with a much lower catalyst loading ( $1 \mathrm{~mol} \%$ ), and $1.72 \mathrm{~g}$ of the desired pyrrole 3a was formed in $85 \%$ yield, highlighting the synthetic utility of this chemistry (eqn (5)). Interestingly, the reaction could also be performed well even in water to afford the desired product $3 \mathrm{a}$ in $80 \%$ yield and no hydration of the ynamide was observed (eqn (6)), ${ }^{\mathbf{1 0 a}-\boldsymbol{c}}$ thus making this protocol more practical and environmentally benign.

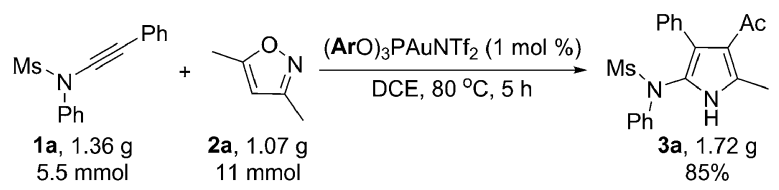

$5.5 \mathrm{mmol} \quad 11 \mathrm{mmol}$

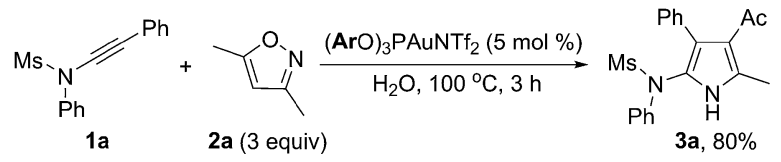

This chemistry can also be used to construct $N$-heteropyrrolizines, which are present in a variety of bioactive molecules. ${ }^{18,12 k}$ For example, treatment of ynamide 1p with isoxazole 4a under the optimized reaction conditions gave the pyrrole $\mathbf{5 p}$, which could be converted into fused 2-aminopyrrole 6 in basic conditions in a one-pot process (63\% two-step overall yield, eqn (7)). Compound 6 might serve as a precursor for the synthesis of lipoxygenase inhibitors (Fig. 1). ${ }^{12 k}$

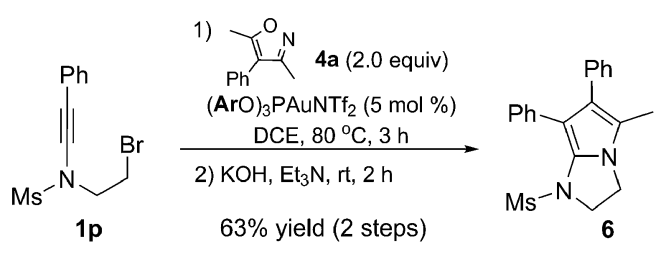

The sulfonamide could be readily transformed into a free amine (Scheme 2). For example, the reaction of ynamide $1 \mathbf{d}$ with isoxazole 2c under the optimized reaction conditions furnished pyrrole 7 in $81 \%$ yield. Nitrogen protection of 7 with a methyl group and subsequent removal of the Ns group using the standard conditions ( $\mathrm{PhSH}, \mathrm{K}_{2} \mathrm{CO}_{3}$ ) resulted in the formation of species $7 \mathbf{a}$ (53\% two-step overall yield). Subsequent deprotection of the benzyl group in 7 a could be realized by performing $\mathrm{MnO}_{2}$-mediated oxidation followed by hydrolysis to afford $7 \mathrm{~b}$ in $56 \%$ yield. ${ }^{13 e}$

To probe the mechanism of this reaction, we first synthesized the alkyl-substituted ynamide 1q as the alkyl-substituted gold carbene is well-known in the gold-catalyzed cycloisomerizations of enynes; [1,2] hydride shift followed by elimination of the gold catalyst was involved as the critical deauration step. ${ }^{\mathbf{1 e}, \mathbf{1 9}}$ Indeed, as depicted in eqn (8), when ynamide $\mathbf{1 q}$ reacted with $\mathbf{2 a}$ under the standard reaction conditions, none of the desired pyrrole was detected and $\alpha, \beta$ unsaturated amide 8 was isolated in $25 \%$ yield. Amide 8 is supposed to be derived from [1,2] hydride shift followed by elimination of the gold catalyst and subsequent hydrolysis. This result indicated that a gold carbene is most likely generated as the key intermediate in this process. On the other hand, the low chemoselectivity in the case of $n$-butyl substituted ynamide
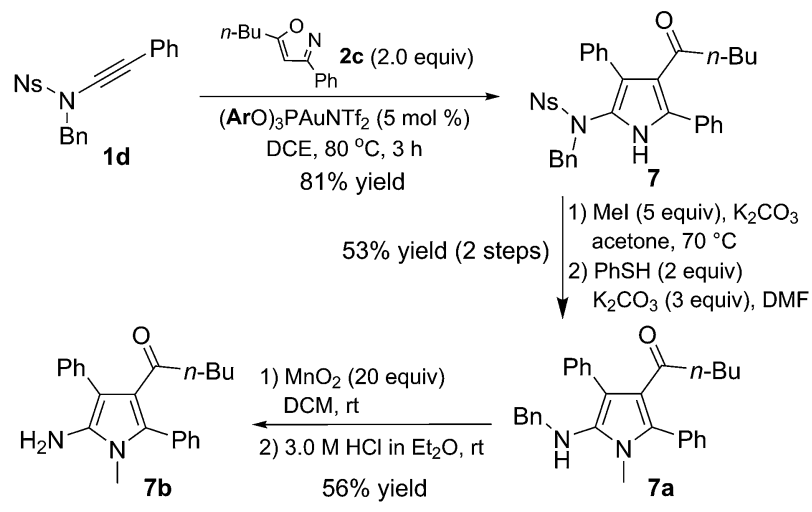<smiles>CCCCC(=O)c1c(-c2ccccc2)c(NCc2ccccc2)n(C)c1-c1ccccc1</smiles>

Scheme 2 Transformation of a sulfonamide into an amine. 
shows the importance of aryl substituents on the ynamides to keep a high reactivity for the reactions in Tables $2-4 .^{20}$

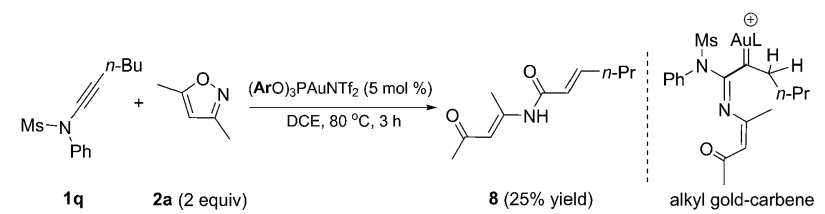

In addition, it was found that a key intermediate $3 H$-pyrrole $5 \mathbf{l}^{\prime}$ could be detected and isolated in the case of the reaction of ynamide $1 \mathbf{i}$ with fully-substituted isoxazole $\mathbf{4 i}$ (Table 4 , entry 12). To further demonstrate this process, we monitored the reaction by ${ }^{1} \mathrm{H}$ NMR spectroscopy, as depicted in Fig. 3. Here, the reaction was performed in the presence of $2 \mathrm{~mol} \%(\mathrm{ArO})_{3} \mathrm{PAuNTf}_{2}$ in $\mathrm{CDCl}_{3}$ in order to better track the reaction intermediates. At the early stage of the reaction, we could clearly observe the formation of the $3 H$-pyrrole $5 \mathbf{l}^{\prime}$, which was gradually transformed into the final $1 H$-pyrrole $\mathbf{5 l}$.

A plausible mechanism to rationalize the formation of pyrrole 3 or 5 is illustrated in Scheme 3, in light of the above experimental observations and density functional theory (DFT) computations (see ESI $\dagger$ for details). ${ }^{21}$ Initially, nucleophilic attack of isoxazole $\mathbf{2}$ or $\mathbf{4}$ to the $\mathrm{Au}(\mathrm{I})$-ligated alkyne of ynamide $\mathbf{1}$ forms vinyl gold intermediate $\mathbf{A}$ by overcoming a moderate barrier (12.2 $\mathrm{kcal} \mathrm{mol}^{-1}$ ). Intermediate $\mathbf{A}$ isomerizes into the gold carbene intermediate $\mathbf{B}$ upon breakage of the isoxalic $\mathrm{N}-\mathrm{O}$ bond, ${ }^{22}$ again requiring an activation energy around $12.0 \mathrm{kcal}$ $\mathrm{mol}^{-1}$. Subsequent 1,5-cyclization ${ }^{23}$ within intermediate $\mathbf{B}$ readily occurs to afford the $\mathrm{Au}(\mathrm{I})$-ligated $3 \mathrm{H}$-pyrrole $\mathbf{C}$, which upon ligand exchange with another ynamide 1 releases $3 H$ pyrrole D. The whole process is highly exothermic with free energy release amounting to $52 \mathrm{kcal} \mathrm{mol}^{-1}$. For 3,5-
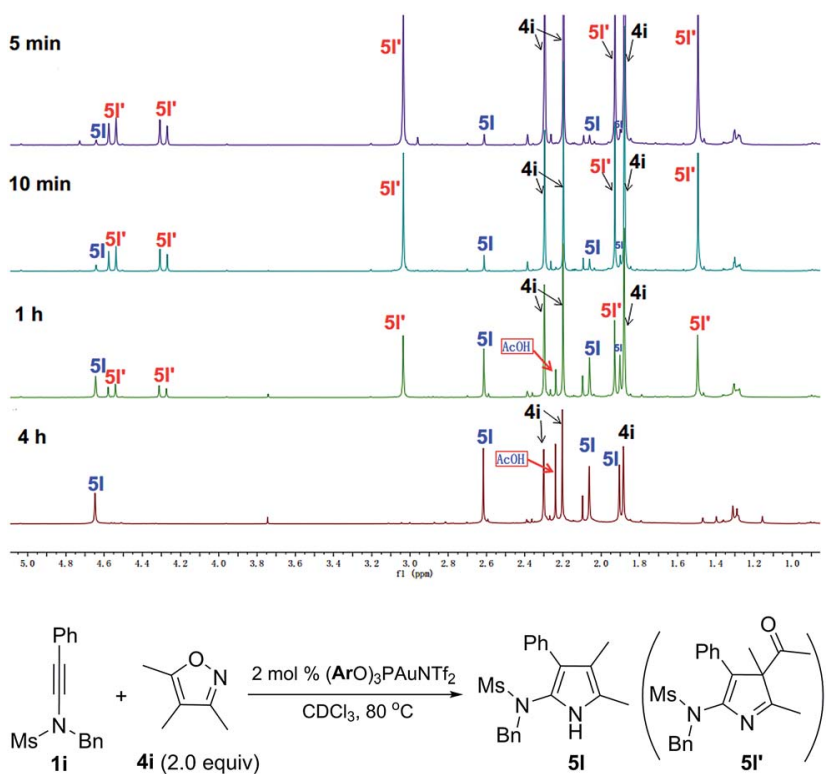

Fig. $3{ }^{1} \mathrm{H}$ NMR monitoring of the reaction of ynamide $1 \mathrm{i}$ with fullysubstituted isoxazole $4 \mathrm{i}$.

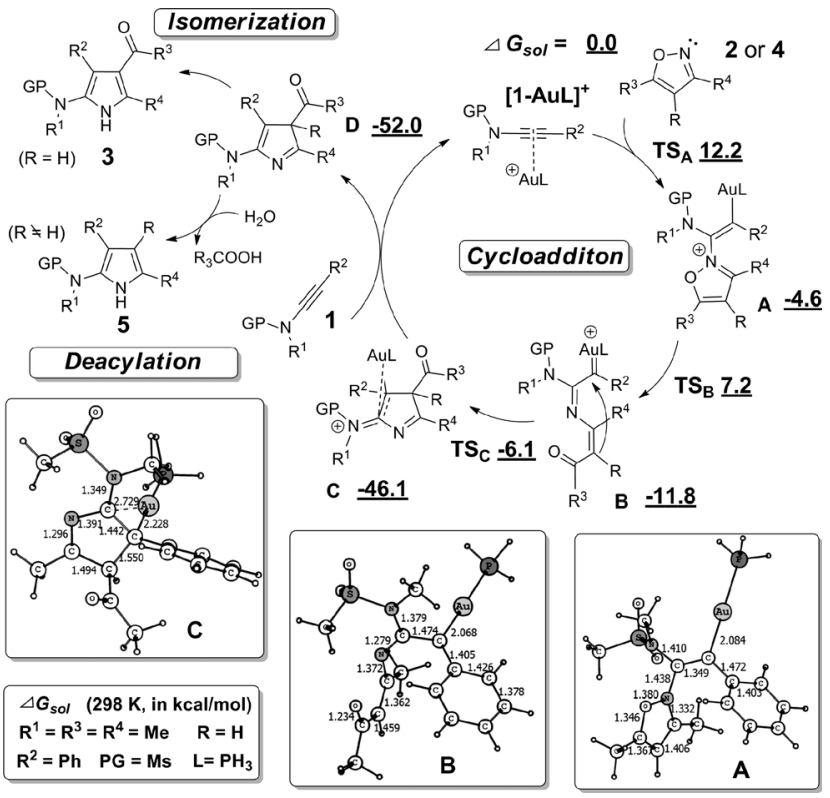

Scheme 3 Plausible reaction mechanism. Theoretical investigations on the reaction pathways for the formation of product $3 \mathrm{~g}$ (Table 2 , entry 7): relative free energies $\left(\Delta G_{\mathrm{sol}}\right.$, in $\left.\mathrm{kcal} \mathrm{mol}^{-1}\right)$ of key intermediates and transition states were computed at the M06/6-31+G(d)/SDD level in 1,2-dichloroethane at $298 \mathrm{~K}$.

disubstituted isoxazoles 2, $3 H$-pyrrole $\mathbf{D}$ readily isomerizes into the final aromatic $1 H$-pyrrole 3 by sigmatropic $\mathrm{H}$-migrations. ${ }^{24}$ In the case of fully-substituted isoxazole substrates 4, D is ultimately transformed into the final $1 H$-pyrrole 5 , presumably by a water-assisted deacylative aromatization. ${ }^{25}$

\section{Conclusions}

In summary, we have developed a novel gold-catalyzed formal $[3+2]$ cycloaddition between ynamides and isoxazoles, leading to the concise and flexible synthesis of polysubstituted 2-aminopyrroles. This methodology makes it possible to introduce four substituents onto a pyrrole ring very freely with high efficiency. Of particular interest, fully substituted isoxazoles also react under deacylation, closing a further gap in the reaction scope. Moreover, an $\alpha$-imino gold carbene is the most likely intermediate based on both mechanistic studies and theoretical calculations, thus providing a new strategy for the generation of gold carbenes, especially in an atom-economic way. Studies to elucidate the detailed mechanism and further synthetic applications of the current protocol are in progress in our laboratory.

\section{Acknowledgements}

We are grateful for the financial support from NSFC (no. 21102119, 21273177 and 21272191), RFDP (20130121110004), NFFTBS (no. J1310024), and the Program for Changjiang Scholars and Innovative Research Team in University. 


\section{Notes and references}

1 For reviews, see: (a) L. Fensterbank and M. Malacria, Acc. Chem. Res., 2014, 47, 953; (b) C. Obradors and A. M. Echavarren, Acc. Chem. Res., 2014, 47, 902; (c) C. Obradors and A. M. Echavarren, Chem. Commun., 2014, 50, 16; (d) A. S. K. Hashmi, Angew. Chem., Int. Ed., 2010, 49, 5232; (e) E. Jiménez-Núñez and A. M. Echavarren, Chem. Rev., 2008, 108, 3326; (f) A. S. K. Hashmi, Chem. Rev., 2007, 107, 3180; $(g)$ A. Fürstner and P. W. Davies, Angew. Chem., Int. Ed., 2007, 46, 3410.

2 (a) N. D. Shapiro and F. D. Toste, J. Am. Chem. Soc., 2007, 129, 4160; (b) G. Li and L. Zhang, Angew. Chem., Int. Ed., 2007, 46, 5156; for reviews, see: (c) J. Xiao and X. Li, Angew. Chem., Int. Ed., 2011, 50, 7226; (d) L. Zhang, Acc. Chem. Res., 2014, 47, 877; (e) H.-S. Yeom and S. Shin, Acc. Chem. Res., 2014, 47, 966.

3 For recent representative examples on gold-catalyzed intermolecular alkyne oxidation, see: (a) J. Schulz, L. Jašíková, A. Škríba and J. Roithová, J. Am. Chem. Soc., 2014, 136, 11513; (b) L. Li, C. Shu, B. Zhou, Y.-F. Yu, X.-Y. Xiao and L.-W. Ye, Chem. Sci., 2014, 5, 4057; (c) F. Pan, S. Liu, C. Shu, R.-K. Lin, Y.-F. Yu, J.-M. Zhou and L.-W. Ye, Chem. Commun., 2014, 50, 10726; (d) S. N. Karad and R.-S. Liu, Angew. Chem., Int. Ed., 2014, 53, 5444; (e) T. Wang, S. Shi, M. M. Hansmann, E. Rettenmeier, M. Rudolph and A. S. K. Hashmi, Angew. Chem., Int. Ed., 2014, 53, 3715; (f) T. Wang, S. Shi, M. Rudolph and A. S. K. Hashmi, Adv. Synth. Catal., 2014, 356, 2337; $(g)$ M. D. Santos and P. W. Davies, Chem. Commun., 2014, 50, 6001; (h) J. Li, K. Ji, R. Zheng, J. Nelson and L. Zhang, Chem. Commun., 2014, 50, 4130; (i) G. Wu, R. Zheng, J. Nelson and L. Zhang, Adv. Synth. Catal., 2014, 356, 1229; (j) P. Nösel, L. N. dos Santos Comprido, T. Lauterbach, M. Rudolph, F. Rominger and A. S. K. Hashmi, J. Am. Chem. Soc., 2013, 135, 15662; (k) L. Wang, X. Xie and Y. Liu, Angew. Chem., Int. Ed., 2013, 52, 13302; (l) S. K. Pawar, C.-D. Wang, S. Bhunia, A. M. Jadhav and R.-S. Liu, Angew. Chem., Int. Ed., 2013, 52, 7559; (m) K. Ji, Y. Zhao and L. Zhang, Angew. Chem., Int. Ed., 2013, 52, 6508; $(n)$ G. Henrion, T. E. J. Chava, X. Le Goff and F. Gagosz, Angew. Chem., Int. Ed., 2013, 52, 6277; (o) S. Ghorpade, M.-D. Su and R.-S. Liu, Angew. Chem., Int. Ed., 2013, 52, 4229.

4 For examples on the utilization of the side products, see: $(a)$ E. P. A. Talbot, M. Richardson, J. M. McKenna and F. D. Toste, Adv. Synth. Catal., 2014, 356, 687; (b) D. B. Huple, S. Ghorpade and R.-S. Liu, Chem.-Eur. J., 2013， 19, 12965; (c) A. Mukherjee, R. B. Dateer, R. Chaudhuri, S. Bhunia, S. N. Karad and R.-S. Liu, J. Am. Chem. Soc., 2011, 133, 15372.

5 To avoid catalyst deactivation by the byproduct pyridine or quinoline, acid has to be used as the additive in some cases. See: (a) C. Shu, L. Li, X.-Y. Xiao, Y.-F. Yu, Y.-F. Ping, J.-M. Zhou and L.-W. Ye, Chem. Commun., 2014, 50, 8689; (b) C. Shu, L. Li, Y.-F. Yu, S. Jiang and L.-W. Ye, Chem. Commun., 2014, 50, 2522; (c) S. Shi, T. Wang, W. Yang,
M. Rudolph and A. S. K. Hashmi, Chem.-Eur. J., 2013, 19, 6576; (d) A. S. K. Hashmi, T. Wang, S. Shi and M. Rudolph, J. Org. Chem., 2012, 77, 7761; (e) M. Xu, T.-T. Ren and C.-Y. Li, Org. Lett., 2012, 14, 4902; (f) W. He, L. Xie, Y. Xu, J. Xiang and L. Zhang, Org. Biomol. Chem., 2012, 10, 3168; (g) D. Qian and J. Zhang, Chem. Commun., 2011, 47, 11152; (h) Y. Luo, G. Zhang, E. S. Hwang, T. A. Wilcoxon and L. Zhang, Beilstein J. Org. Chem., 2011, 7, 596; (i) L. Ye, W. He and L. Zhang, J. Am. Chem. Soc., 2010, 132, 8550; (j) L. Ye, L. Cui, G. Zhang and L. Zhang, J. Am. Chem. Soc., 2010, 132, 3258.

6 (a) Z. Li, D. A. Capretto, R. O. Rahaman and C. He, J. Am. Chem. Soc., 2007, 129, 12058; (b) Z. Li, X. Ding and C. He, J. Org. Chem., 2006, 71, 5876.

7 For selected reviews, see: (a) S. Fantauzzi, A. Caselli and E. Gallo, Dalton Trans., 2009, 5434; (b) M. M. Diaz-Requejo and P. J. Perez, Chem. Rev., 2008, 108, 3379; (c) P. Mueller and C. Fruit, Chem. Rev., 2003, 103, 2905.

8 (a) D. J. Gorin, N. R. Davis and F. D. Toste, J. Am. Chem. Soc., 2005, 127, 11260; (b) N. D. Shapiro and F. D. Toste, J. Am. Chem. Soc., 2007, 129, 4160; (c) A. Wetzel and F. Gagosz, Angew. Chem., Int. Ed., 2011, 50, 7354; (d) B. Lu, Y. Luo, L. Liu, L. Ye, Y. Wang and L. Zhang, Angew. Chem., Int. Ed., 2011, 50, 8358; (e) Y. Xiao and L. Zhang, Org. Lett., 2012, 14, 4662; (f) Z.-Y. Yan, Y. Xiao and L. Zhang, Angew. Chem., Int. Ed., 2012, 51, 8624; $(g)$ Y. Tokimizu, S. Oishi, N. Fujii and H. Ohno, Org. Lett., 2014, 16, 3138; $(h)$ During the preparation of this manuscript, an intramolecular reaction between alkyne and $2 \mathrm{H}$-azirine groups was reported: A. Prechter, G. Henrion, P. F. dit Bel and F. Gagosz, Angew. Chem., Int. Ed., 2014, 53, 4959.

9 (a) C. Li and L. Zhang, Org. Lett., 2011, 13, 1738; (b) P. W. Davies, A. Cremonesi and L. Dumitrescu, Angew. Chem., Int. Ed., 2011, 50, 8931; (c) E. Chatzopoulou and P. W. Davies, Chem. Commun., 2013, 49, 8617; (d) H.-H. Hung, Y.-C. Liao and R.-S. Liu, J. Org. Chem., 2013, 78, 7970.

10 For recent reviews on ynamide reactivity, see: (a) X.-N. Wang, H.-S. Yeom, L.-C. Fang, S. He, Z.-X. Ma, B. L. Kedrowski and R. P. Hsung, Acc. Chem. Res., 2014, 47, 560; (b) K. A. DeKorver, H. Li, A. G. Lohse, R. Hayashi, Z. Lu, Y. Zhang and R. P. Hsung, Chem. Rev., 2010, 110, 5064; (c) G. Evano, A. Coste and K. Jouvin, Angew. Chem., Int. Ed., 2010, 49, 2840; for recent selected examples on the goldcatalyzed reactions of ynamides, see: (d) S. K. Pawar, D. Vasu and R.-S. Liu, Adv. Synth. Catal., 2014, 356, 2411; (e) E. Rettenmeier, A. M. Schuster, M. Rudolph, F. Rominger, C. A. Gade and A. S. K. Hashmi, Angew. Chem., Int. Ed., 2013, 52, 5880; $(f)$ S. J. Heffernan, J. M. Beddoes, M. F. Mahon, A. J. Hennessy and D. R. Carbery, Chem. Commun., 2013, 49, 2314; $(g)$ S. N. Karad, S. Bhunia and R.-S. Liu, Angew. Chem., Int. Ed., 2012, 51, 8722; (h) R. B. Dateer, B. S. Shaibu and R.-S. Liu, Angew. Chem., Int. Ed., 2012, 51, 113; (i) R. B. Dateer, K. Pati and R.-S. Liu, Chem. Commun., 2012, 48, 7200.

11 (a) T. M. V. D. Pinho e Melo, Curr. Org. Chem., 2005, 9, 925; (b) T. V. Hansen, P. Wu and V. V. Fokin, J. Org. Chem., 2005, 
70, 7761; (c) S. Tang, J. He, Y. Sun, L. He and X. She, Org. Lett., 2009, 11, 3982; (d) O. Debleds, E. Gayon, E. Ostaszuk, E. Vrancken and J.-M. Campagne, Chem.-Eur. J., 2010, 16, 12207; (e) A. G. Griesbeck, M. Franke, J. Neudörfl and H. Kotaka, Beilstein J. Org. Chem., 2011, 7, 127.

12 For selected examples, see: (a) T. B. Kumar, C. Sumanth, S. Vaishaly, M. S. Rao, K. B. C. Sekhar, C. L. T. Meda, A. Kandale, D. Rambabu, G. R. Krishna, C. M. Reddy, K. S. Kumar, K. V. L. Parsa and M. Pal, Bioorg. Med. Chem. Lett., 2012, 22, 5639; (b) L. V. Frolova, N. M. Evdokimov, K. Hayden, I. Malik, S. Rogelj, A. Kornienko and I. V. Magedov, Org. Lett., 2011, 13, 1118; (c) H. B. Jalani, A. N. Pandya, A. B. Baraiya, J. C. Kaila, D. H. Pandya, J. A. Sharma, V. Sudarsanam and K. K. Vasu, Tetrahedron Lett., 2011, 52, 6331; (d) M. B. Wallace, M. E. Adams, T. Kanouni, C. D. Mol, D. R. Dougan, V. A. Feher, S. M. O'Connell, L. Shi, P. Halkowycz and Q. Dong, Bioorg. Med. Chem. Lett., 2010, 20, 4156; (e) V. Onnis, A. De Log, M. T. Cocco, R. Fadda, R. Meleddu and C. Congiu, Eur. J. Med. Chem., 2009, 44, 1288; (f) M. T. Migawa, J. C. Drach and L. B. Townsend, J. Med. Chem., 2005, 48, 3840; $(g)$ A. Lauria, M. Bruno, P. Diana, P. Barraja, A. Montalbano, G. Cirrincione, G. Dattolo and A. M. Almerico, Bioorg. Med. Chem., 2005, 13, 1545; (h) M. T. Cocco, C. Congiu and V. Onnis, Bioorg. Med. Chem., 2003, 11, 495; (i) M. Tanaka, Y. Sasaki, Y. Kimura, T. Fukui and Y. Ukai, BJU Int., 2003, 92, 1031; (j) C. E. Stephens, T. M. Felder, J. W. Sowell Sr, G. Andrei, J. Balzarini, R. Snoeck and E. D. Clercq, Bioorg. Med. Chem., 2001, 9, 1123; (k) S. Laufer, H. G. Striegel and G. Dannhardt, Ger. Offen. DE 4419 315A1, 1995; $(l)$ S. M. Bennet, N. Nguyen-Ba and K. K. Ogilvie, J. Med. Chem., 1990, 33, 2162; (m) J. Kobayshi, J. Cheng, Y. Kikuchi, M. Ishibashi, S. Yamamura, Y. Ohizumi, T. Ohta and S. Nozoe, Tetrahedron Lett., 1990, 31, 4617.

13 For recent examples on 2-aminopyrrole synthesis, see: $(a)$ X. Qi, H. Xiang, Q. He and C. Yang, Org. Lett., 2014, 16, 4186; (b) X. Wang, X.-P. Xu, S.-Y. Wang, W. Zhou and S.-J. Ji, Org. Lett., 2013, 15, 4246; (c) W. Yu, W. Chen, S. Liu, J. Shao, Z. Shao, H. Lin and Y. Yu, Tetrahedron, 2013, 69, 1953; (d) L. V. Frolova, N. M. Evdokimov, K. Hayden, I. Malik, S. Rogelj, A. Kornienko and I. V. Magedov, Org. Lett., 2011, 13, 1118; (e) P. Fontaine, G. Masson and J. Zhu, Org. Lett., 2009, 11, 1555; (f) E. Barnea, S. Majumder, R. J. Staples and A. L. Odom, Organometallics, 2009, 28, 3876; (g) T.-C. Chien, E. A. Meade, J. M. Hinkley and L. B. Townsend, Org. Lett.,
2004, 6, 2857; (h) V. Nair, A. U. Vinod and C. Rajesh, J. Org. Chem., 2001, 66, 4427.

14 For recent $\mathrm{Zn}(\mathrm{OTf})_{2}$-catalyzed metathesis reactions between 3-en-1-ynamides and nitrosoarenes, see: S. A. Gawade, D. B. Huple and R.-S. Liu, J. Am. Chem. Soc., 2014, 136, 2978.

15 S. Kramer, Y. Odabachian, J. Overgaard, M. Rottländer, F. Gagosz and T. Skrydstrup, Angew. Chem., Int. Ed., 2011, 50, 5090.

16 For examples on gold-catalyzed oxidative-cyclopropanation, see: (a) K.-B. Wang, R.-Q. Ran, S.-D. Xiu and C.-Y. Li, Org. Lett., 2013, 15, 2374; (b) D. Vasu, H.-H. Hung, S. Bhunia, S. A. Gawade, A. Das and R.-S. Liu, Angew. Chem., Int. Ed., 2011, 50, 6911.

17 ESI. $\dagger$

18 (a) Z. Li, X. Xu, Z. Ye, X. Qian, X. Shao, Z. Xu, B. Zeng and G. Song, PCT Int. Appl. WO 2013007168A1, 2013; (b) H. B. Lowman and S. Liu, PCT Int. Appl. WO 2013192546A1, 2013; (c) W. G. Kerr, PCT Int. Appl. WO 2010045199A2, 2010; (d) A. Lagrange, PCT Int. Appl. WO 2007071686A1, 2007; (e) J. Cotteret and A. Lagrange, Eur. Pat. Appl. EP 1428510A1, 2004; $(f)$ T. D. Mckee and R. K. Suto, PCT Int. Appl. WO 2003073999A2, 2003; $(g)$ G. Lang, PCT Int. Appl. WO 2001066071A1, 2001; $(h)$ M. P. Audousset, Eur. Pat. Appl. EP 1002520A1, 2000; $(i)$ L. Vidal and G. Malle, PCT Int. Appl. WO 9735554A1, 1997.

19 (a) L. Zhang, J. Sun and S. A. Kozmin, Adv. Synth. Catal., 2006, 348, 2271; (b) P. W. Davies, A. Cremonesi and N. Martin, Chem. Commun., 2011, 47, 379; (c) B. Lu, C. Li and L. Zhang, J. Am. Chem. Soc., 2010, 132, 14070.

20 The DFT studies on substituent effects are given in the ESI. $\dagger$ 21 For theoretical calculations involving $\alpha$-oxo gold carbenes, see: (a) J. Schulz, L. Jašíková, A. Škríba and J. Roithová, J. Am. Chem. Soc., 2014, 136, 11513; (b) B. Lu, Y. Li, Y. Wang, D. H. Aue, Y. Luo and L. Zhang, J. Am. Chem. Soc., 2013, 135, 8512 .

22 C. Kashima, N. Mukai, Y. Yamamoto, Y. Tsuda and Y. Omote, Heterocycles, 1977, 7, 241.

23 J. R. Manning and H. M. L. Davies, J. Am. Chem. Soc., 2008, 130, 8602.

24 W. Friedrichsen, T. Traulsen, J. Elguero and A. R. Katritzky, Adv. Heterocycl. Chem., 2000, 76, 85.

25 For selected examples of acid-catalyzed deacylation of pyrroles, see: (a) A. E. Ondrus, H. Ü. Kaniskan and M. Movassaghi, Tetrahedron, 2010, 66, 4784; (b) F. Barrero, J. F. Sánchez, J. E. Oltra and D. J. Teva, J. Heterocycl. Chem., 1991, 28, 939; (c) K. M. Smith, M. Miura and H. D. Tabba, J. Org. Chem., 1983, 48, 4779. 